Brazilian Journal

of Chemical

Engineering

\title{
DETERMINATION OF REACTIVITY AND THERMODYNAMIC ANALYSIS OF NICKEL-BASED OXYGEN CARRIERS FOR CHEMICAL-LOOPING COMBUSTION
}

\author{
Adolfo L. Figueredo ${ }^{1 *}$, Fabíola C. Carvalho², José C. Nascimento ${ }^{2}$, \\ Juan A. C. Ruiz ${ }^{2}$, Osvaldo Chiavone-Filho ${ }^{1}$ and Camila G. Pereira ${ }^{1}$ \\ ${ }^{1}$ Universidade Federal do Rio Grande do Norte, Departamento de Engenharia Química, Natal, RN, Brasil. \\ E-mail: adolfofigueredo@outlook.com - ORCID: 0000-0002-2685-2223; ORCID: 0000-0002-1752-5757; ORCID: 0000-0003-2472-9755 \\ ${ }^{2}$ Instituto Senai de Inovação em Energias Renováveis, Laboratório de Sustentabilidade, Natal, RN, Brasil. ORCID: 0000-0001-6101-2441; \\ ORCID: 0000-0001-5806-1373; ORCID: 0000-0001-8990-0061
}

(Submitted: June 20, 2018 ; Revised: February, 20, 2019 ; Accepted: February, 20, 2019)

\begin{abstract}
This work aimed to study nickel-based oxygen carriers (OC) for Chemical Looping Combustion (CLC) using $\mathrm{H}_{2}$ and $\mathrm{CH}_{4}$ as fuel. The reactivity and reaction kinetics of the $\mathrm{OC}$ were investigated, applying the shrinking core, nucleation and diffusion models in three dimensions, as well as whether the $\mathrm{OC}$ is thermodynamically favorable for the reaction. The results showed that the OC achieved high conversion for both fuels, proving to be quite reactive, while the fuel gas concentration and the temperature have a strong effect on the solids conversion. For the $\mathrm{H}_{2}$ combustion, the reaction rate can be described well by the shrinking core model, whereas for $\mathrm{CH}_{4}$ the nucleation model may better represent the experimental data. With respect to reactions that occur in the reduction reactor with the $\mathrm{NiO} / \mathrm{Ni}$ redox system, it was observed that, for the investigated temperatures used in CLC, high values of the equilibrium constant were obtained, showing that practically complete conversion of the fuels is possible.

Keywords: Chemical looping combustion; Nickel oxide; Oxygen carrier.
\end{abstract}

\section{INTRODUCTION}

Chemical looping combustion (CLC) is a technology used for power generation with the possibility of $\mathrm{CO}_{2}$ capture, considered one of the best alternatives to reduce $\mathrm{CO}_{2}$ emission to the atmosphere (Adanez et al., 2012). The complete process occurs in two connected fluidized bed reactors (oxidation/ air reactor and reduction/combustion reactor), where the energy is generated by the burning of the fuel that occurs in the reduction reactor. The oxygen required for combustion is provided by the transfer of air to the fuel by oxygen carriers (OCs), which circulate between the two reactors, oxidizing in the air reactor and reduced thereafter in the combustion reactor. Thus, there is no need for an air separation unit $\left(\mathrm{N}_{2}+\mathrm{O}_{2}\right)$ and no emission of NOx compounds. An easy capture of $\mathrm{CO}_{2}$ is provided in CLC, considering that the output current in the reduction reactor would be composed only of $\mathrm{CO}_{2}$ and $\mathrm{H}_{2} \mathrm{O}$ (Pröll et al., 2010; Ortiz et al., 2011).

In order to develop this technology, it is necessary to choose the appropriate oxygen carrier, which must have characteristics such as high mechanical and thermal stability (high melting point), be susceptible to several redox cycles, present high reactivity and high selectivity for complete conversion of fuel to $\mathrm{CO}_{2}$ and $\mathrm{H}_{2} \mathrm{O}$ (Forutan et al., 2015). Iron, copper and nickel have been selected as the most promising candidates (Adánez et al., 2004), with nickel being the most interesting for the CLC process due to its strong catalytic properties. This particular material presents

\footnotetext{
* Corresponding author: Adolfo L. Figueredo - E-mail: adolfofigueredo@outlook.com
} 
high reactivity and selectivity for $\mathrm{H}_{2}$, and resistance to agglomeration. High melting points of nickel oxide $(2268 \mathrm{~K})$ and nickel metal $(1728 \mathrm{~K})$ allow working at higher temperatures (1200-1400 K) in the CLC system in relation to other oxides, such as $\mathrm{CuO}$. However, using nickel-based materials, thermodynamic limitations prevent the complete conversion of methane into $\mathrm{CO}_{2}$ and $\mathrm{H}_{2} \mathrm{O}$ in the fuel reactor, due to the presence of $\mathrm{CO}$ and $\mathrm{H}_{2}$ at equilibrium conditions. Using a nickelbased oxygen carrier for a CLC system, the possible reactions that can occur in the reduction reactor, using $\mathrm{CH}_{4}$ and $\mathrm{H}_{2}$ as fuel, are shown below (Ortiz et al., 2011; Han et al., 2016). In view of the multiple routes of reduction of $\mathrm{NiO}$ by $\mathrm{CH}_{4}$, it is necessary to study the activity of the $\mathrm{OC}$ in relation to $\mathrm{CH}_{4}$, proposing kinetic models that can describe the rate of solids conversion, in order to predict conversion data to be used to calculate retention time and solids circulation rate in a CLC plant.

$$
\begin{aligned}
& \mathrm{CH}_{4}+4 \mathrm{NiO} \leftrightarrow \mathrm{CO}_{2}+2 \mathrm{H}_{2} \mathrm{O}+4 \mathrm{Ni} \\
& \mathrm{CH}_{4}+\mathrm{NiO} \leftrightarrow \mathrm{CO}+\mathrm{Ni}+2 \mathrm{H}_{2} \\
& \mathrm{CH}_{4}+\mathrm{H}_{2} \mathrm{O} \leftrightarrow \mathrm{CO}+3 \mathrm{H}_{2} \\
& \mathrm{CH}_{4}+2 \mathrm{H}_{2} \mathrm{O} \leftrightarrow \mathrm{CO}_{2}+4 \mathrm{H}_{2} \\
& \mathrm{CH}_{4} \leftrightarrow \mathrm{C}+2 \mathrm{H}_{2} \\
& \mathrm{C}+\mathrm{H}_{2} \mathrm{O} \leftrightarrow \mathrm{CO}+\mathrm{H}_{2} \\
& \mathrm{H}_{2}+\mathrm{NiO} \leftrightarrow \mathrm{H}_{2} \mathrm{O}+\mathrm{Ni} \\
& 2 \mathrm{Ni}+\mathrm{O}_{2} \leftrightarrow 2 \mathrm{NiO}
\end{aligned}
$$

The oxygen carrying capacity $\left(\mathrm{R}_{\mathrm{O}}\right)$ is a characteristic of the oxygen carrier fundamental to the design and operation of the process. $\mathrm{R}_{\mathrm{O}}$, defined by the ratio between the mass difference reduced and oxidized by the oxidized mass (Equation 1), is an indicator of the amount of oxygen that can be transferred by the OC between the reactors and which will be available for the reaction. The determination of $\mathrm{R}_{\mathrm{OC}}$ can be performed from the reactions ( $\mathrm{r} 1)$, (r7) and (r8); however, this value is altered when working with OC supported on inert material (Abad et al., 2007a). The actual oxygen carrying capacity $\left(\mathrm{R}_{\mathrm{OC}}\right)$ depends on the fraction of the metal oxide contained in the $\mathrm{OC}\left(\mathrm{x}_{\mathrm{ox}}\right)$, so the maximum available oxygen for the different OCs is expressed by Equation 2.

$\mathrm{R}_{\mathrm{O}}=\frac{\mathrm{M}_{\mathrm{ox}}-\mathrm{M}_{\mathrm{re}}}{\mathrm{M}_{\mathrm{ox}}}$
$\mathrm{R}_{\mathrm{OC}}=\mathrm{R}_{\mathrm{O}} \mathrm{x}_{\mathrm{oc}}$

where $\mathrm{M}_{\mathrm{ox}}$ and $\mathrm{M}_{\mathrm{re}}$ are the masses of the carrier in its oxidized and reduced forms, respectively.

The use of $\mathrm{Al}_{2} \mathrm{O}_{3}$ as a support for nickel-based oxygen carriers has been extensively studied in the literature because of its good fluidization properties and thermal stability. However, its main disadvantage for $\mathrm{NiO}$ based $\mathrm{OC}$ is the formation of $\mathrm{NiAl}_{2} \mathrm{O}_{4}$. At high temperatures of calcination $(>1073 \mathrm{~K})$, the $\mathrm{NiO}$ can react with the alumina, forming nickel aluminate, which has lower reactivity when compared to $\mathrm{NiO}$ (Dueso et al., 2012).

Jerndal et al. (2006) showed a broad thermodynamic analysis of the different redox systems considered for CLC. They identified $\mathrm{Cu}, \mathrm{Ni}, \mathrm{Co}, \mathrm{Fe}$, and $\mathrm{Mn}$ oxides as thermodynamically favorable in terms of the equilibrium constant for the $\mathrm{CH}_{4}, \mathrm{H}_{2}$ and $\mathrm{CO}$ conversions. At temperatures and pressures relevant to CLC, hydrocarbons are not thermodynamically stable and amounts of $\mathrm{CO}_{2}, \mathrm{H}_{2} \mathrm{O}, \mathrm{CO}$ and $\mathrm{H}_{2}$ may appear depending on the redox system (Adanez et al., 2012). In addition, with the reduction of the oxide at the surface, $\mathrm{CH}_{4}$ conversion may proceed through the reduction of $\mathrm{NiO}$ or the combination of vapor reforming (reaction 3 ) and secondary reactions, such as decomposition to form $\mathrm{H}_{2}$ (reaction 5). The concentration of synthesis gas in the reactor exhaust may be the result of the partial oxidation reaction between $\mathrm{CH}_{4}$ and $\mathrm{NiO}$ or the steam reforming reaction and secondary reactions in equilibrium (Hann et al., 2016a). Thus, it is necessary to study thermodynamically the set of these reactions in order to obtain a complete conversion and to obtain data for the energy balance necessary for the use of the system in a self-thermal way.

The knowledge of the reduction reaction kinetics is essential for the design of the CLC system. For modeling purposes, it is fundamental to know the kinetics under different operating conditions. However, in most studies found in the literature only a partial analysis or studies without considering the effect of gas concentration or temperature were performed. Consequently, limited information can be extracted from the reactivity data for design purposes, although they can be used to compare different oxygen carriers.

There are several types of resistances that can affect the reaction rate of $\mathrm{OC}$. The mass transfer resistances in the gas film and on the surface of the ash layer are reduced by the experimental conditions used in the process, so that the resistance is controlled by the chemical reaction. To determine the kinetic parameters of the OC with respect to the reduction $\left(\mathrm{CH}_{4}\right.$ and $\left.\mathrm{H}_{2}\right)$, the Shrinking core model with the process controlled by the chemical reaction in the solid has been the adopted most in the literature (Zhou et al., 2014). 
In many gas-solid reactions, with formation of a solid product, oxidation and reduction of solid oxygen carriers can be approached by a nucleation process. According to the nucleation and growth models of nuclei, the process proceeds with the generation of metallic nuclei, which grow later and eventually overlap. The rate of reaction increases as the number of nuclei increases during the first moment of the reaction, the so-called induction period. After this point, the reaction will occur uniformly on the solid surface, advancing later uniformly to the inner part of the solid (Adanez et al., 2012). Thus, conversion versus time curves are characterized by a sigmoidal behavior, often described by the Avrami model.

Kinetic models have been used to describe kinetics of $\mathrm{NiO}$ reduction using different fuels. Han et al. (2016ab) presented a two-part study where they proposed a mathematical model to describe the reaction kinetics of $\mathrm{NiO}-\mathrm{CH}_{4}$ and to estimate parameters, evaluating the understanding of the reaction system and its controversies. For the authors, one of the inconsistencies found in the literature for the reduction of $\mathrm{NiO}$ with $\mathrm{CH}_{4}$ is in the modeling by different reaction networks. Besides, the reduced $\mathrm{Ni}$ can catalyze several reactions such as $\mathrm{CH}_{4}$ reforming, the shift reaction and carbon formation, which occur simultaneously. In a previous study, the authors had analyzed the reactivity of OC in TGA (Han et al., 2014) and proposed a model to evaluate the physical and chemical properties of the reaction rate. In this study, a two-phase model was proposed to describe the interactions between gas diffusion in the crucible (diffusion) and through the particle bed and within the pores (interparticle diffusion). In another work, Nordness et al. (2016) studied the pressure effect on the reactivity of $\mathrm{Ni}$ and $\mathrm{Cu}$-based OCs using synthesis gas or methane in a bench-scale fixed-bed reactor. The results were used to determine the reaction kinetics for CLC at high pressures. The authors observed that the increase in pressure provided greater carbon deposition in the $\mathrm{OC}$, and decreased the selectivity of $\mathrm{CO}_{2}$ for NiO. The numerical model with semiempirical correlation for the effect of kinetic pressure described the experimental results well, noting that the increase in pressure has a negative effect on kinetics of oxidation and reduction of the $\mathrm{CO}$.

The literature still does not show any consensus as to which physical model describes the reaction kinetics of nickel-based OC, and still does not exhibit a single model to describe the kinetics of an OC, given the complexity of the process and the different variables that alter the solid reduction reaction rate. Therefore, in order to contribute to consolidation of technology, it is worth a study to evaluate the physical processes that occur in the solid, using models that describe the reduction reaction rate of the solid, that are essential to define the inventory of solids and the circulation rate of solids in a CLC plant. In addition, as a consequence of the large number of reactions that can occur in a reduction reactor, it is essential to study them from the thermodynamic point of view, providing an analysis based on the physical concepts of the equilibrium of reactions.

In this sense, this work aimed to investigate the performance of these nickel-based OCs, studying the reactivity for two fuels $\left(\mathrm{H}_{2}\right.$ and $\left.\mathrm{CH}_{4}\right)$, evaluating the effect of increasing temperature and concentration, as well as proposing to a practical approach to the kinetics of the reduction $\mathrm{NiO} / \mathrm{Ni}$, considering the 3 main physical models and their associated resistances for solid conversion control, in order to obtain a satisfactory prediction of data in line with a thermodynamic study in terms of equilibrium constant and reaction coordinates for the multiple reactions that occur in the reduction reactor.

\section{EXPERIMENTAL PROCEDURE}

Nickel-based OCs synthesized by the research group at the Carbochemistry Institute (University of Zaragoza, Spain) were used according to the methodology described in (Adanez et al., 2009) and supplied to the Natural Gas Processing Laboratory (LPG) of the Gas Technology Center and Renewable Energy (CTGAS-ER), where the reactions were performed. The nickel-based $\mathrm{OC}$ has surface area characteristics of $49 \mathrm{~g} / \mathrm{m}^{2}$, density of $2500 \mathrm{~kg} / \mathrm{m}^{3}$ and diameter of $200 \pm 100 \mu \mathrm{m}$. For the study of the reactivity of the nickel-based $\mathrm{OC}$, a thermobalance (1200C LTG-01, CI PRECION) was used, which is a system basically consisting of a set of thermocouples, furnace, reactor and a microbalance. The reactor consists of a quartz tube coupled inside an oven that can be operated at high temperatures (Tmax of 1200 ${ }^{\circ} \mathrm{C}$ ). The oxygen carriers (40 to $60 \mathrm{mg}$ ) were placed in a sample port consisting of a mesh basket formed of platinum wire to reduce the resistance to mass transfer around the sample, where it was heated to a desired temperature and then subjected to alternating reduction and oxidation cycles. During the oxidation cycle, a gas stream containing $100 \%$ atmospheric air flowed into the reactor, while in the reduction cycle a mixture of $10 \%$ of $\mathrm{CH}_{4}, 22 \%$ and $10 \%$ of $\mathrm{H}_{2}$ diluted in $\mathrm{N}_{2}$ was used as fuel, with a flow rate of $416 \mathrm{~mL} /$ min for both mixtures and air, at ambient pressure. The inlet gases were initially heated to a temperature of $393 \mathrm{~K}$ by a resistance along the pipes. To prevent the reducing and oxidation reactant gas from mixing, a stream of $\mathrm{N}_{2}$ flowed between the two steps. The weight variation and temperature were continuously recorded on a computer. Several cycles (an average 5 cycles per analysis) were performed for each sample 
at atmospheric pressure and the solids conversion calculated by Equation 3 was analyzed. For the purposes of calculating OC reactivity, data from cycle 3 were used, since after the first cycle the carriers were stabilized, presenting similar behavior in subsequent cycles.

$$
X_{S}=\frac{M-M_{r e}}{M_{o x}-M_{r e}}=\frac{M-M_{r e}}{R_{O c} M_{o x}}
$$

where $\mathrm{M}$ is the momentary mass and the denominator is the maximum oxygen transport between the OC fully oxidized $\left(\mathrm{m}_{\mathrm{ox}}\right)$ and reduced $\left(\mathrm{m}_{\mathrm{re}}\right)$, which can also be expressed as the product of the actual oxygen carrying capacity $\left(\mathrm{R}_{\mathrm{OC}}\right)$ and the mass of OC totally oxidized.

The conversion rate, following the kinetics, can be described by Equation 4:

$$
\frac{\mathrm{dX}_{\mathrm{S}}}{\mathrm{dt}}=\mathrm{k}(\mathrm{T}) \mathrm{f}\left(\mathrm{X}_{\mathrm{S}}\right)
$$

where $f\left(X_{S}\right)$ is the reaction model that describes the physical or chemical properties during the reaction, and $\mathrm{k}(\mathrm{T})$ is the kinetic constant described by the Arrhenius equation (Equation 5).

$$
\mathrm{k}=\mathrm{A}_{0} \mathrm{e}^{-\mathrm{E}_{\mathrm{a}} / \mathrm{RT}}
$$

Integrating both sides of Equation 4 under isothermal conditions, Equation 6 can be obtained.

$$
\mathrm{g}(\mathrm{x})=\mathrm{kt}
$$

where $\mathrm{t}$ is the maximum time for complete conversion of solids $\left(X_{S}\right)$ and $g(x)$ :

$$
g(x)=\int \frac{d X_{S}}{f\left(X_{S}\right)}
$$

The determination of the kinetic model of nickelbased $\mathrm{OC}$ reduction using $\mathrm{H}_{2}$ and $\mathrm{CH}_{4}$ as fuel was performed by adjusting the mathematical equations of the models (Table 1), where a treatment of the kinetic curves was performed to determine the reaction rate constant $(\mathrm{k})$ represented by the linear regression coefficients of the function $\mathrm{g}(\mathrm{x})$ as a function of time
(Equation 6). The criterion for selecting the best kinetic model is based on the value of the linear correlation coefficient. For the calculations, conversions up to $80 \%$ were used, because above this conversion, the solids conversion rate declines, entering the stationary state.

Hancock and Sharp (1972) described a convenient method to compare the kinetics of isothermal reactions of the solid state and obtaining the parameter $\mathrm{m}$. Later, Luo et al. (2014) using the same methodology for iron-based OCs identified $\mathrm{m}$ and the mechanism of reaction. The experimental data can be expressed by Equations 8 and 9:

$$
\begin{aligned}
& 1-X_{S}=e^{n t^{m}} \\
& \ln \left(-\ln \left(1-X_{S}\right)=m \ln (t)+\ln (n)\right.
\end{aligned}
$$

For the calculation of the other kinetic parameters, such as the activation energy $\left(\mathrm{E}_{\mathrm{a}}\right)$ and the preexponential factor $\left(A_{0}\right)$, the reaction rate constant was calculated at different temperatures $(1073,1123,1173$ and $1223 \mathrm{~K}$ ), using $\mathrm{H}_{2}$ at $10 \%$ by volume. The activation energy and the pre-exponential factor of the Arrhenius equation were obtained from the linearization of the Arrhenius equation (Equation 5).

The thermodynamic analysis consisted of evaluating the equilibrium constant of the reactions that occur in the reduction reactor for the $\mathrm{NiO} / \mathrm{Ni}$ redox system, reactions (1) to (7), from which it was possible to obtain information on how thermodynamically favorable the redox system is for complete conversion of reagents into products. Besides, it was possible to enable the calculation of the equilibrium concentrations by determining the reaction coordinate, through Equation 10 .

$$
\prod_{i}\left(\hat{\phi}_{i} \mathrm{y}_{\mathrm{i}}\right)^{v_{\mathrm{i}}}=\mathrm{K}_{\mathrm{eq}}\left(\frac{\mathrm{P}}{\mathrm{P}^{0}}\right)^{-v}
$$

where $y_{i}$ is the mole fraction of the component $i, \phi_{i}$ di is the fugacity coefficient, $\mathrm{K}_{\mathrm{eq}}$ is the equilibrium constant, $\mathrm{P}$ is the system pressure, $\mathrm{P}^{0}$ is the reference pressure (1 bar), $\mathrm{V}_{\mathrm{i}}$ is the stoichiometric coefficient of the component $\mathrm{i}$, and $\mathrm{v}$ is the overall reaction coefficient.

Table 1. Kinetic models used in this study (LUO et al., 2014).

\begin{tabular}{ccc}
\hline Kinetic Model & $\mathbf{F}\left(\mathbf{X}_{\mathbf{S}}\right)$ & $\mathbf{g}(\mathbf{x})$ \\
\hline Shrinking core & $2\left(1-\mathrm{X}_{\mathrm{S}}\right)^{1 / 2}$ & $1-\left(1-\mathrm{X}_{\mathrm{S}}\right)^{1 / 2}$ \\
Nucleation & $\mathrm{m}\left(1-\mathrm{X}_{\mathrm{S}}\right)\left[-\ln \left(1-\mathrm{X}_{\mathrm{S}}\right)\right]^{1-1 / \mathrm{m}}$ & {$\left[-\ln \left(1-\mathrm{X}_{\mathrm{S}}\right)\right]^{1 / \mathrm{m}}$} \\
Diffusion & $\frac{\mathrm{m}}{2}\left(1-\mathrm{X}_{\mathrm{S}}\right)^{2 / \mathrm{m}\left[1-\left(1-\mathrm{X}_{\mathrm{S}}\right)^{1 / \mathrm{m}}\right]}$ & {$\left[1-\left(1-\mathrm{X}_{\mathrm{S}}\right)^{1 / \mathrm{m}}\right]^{2}$} \\
\hline
\end{tabular}

$\mathrm{m}$ is the exponential factor that describes the process of development of nuclei for the nucleation model and the speed at which the diffusion mechanism occurs. 
Since the pressure ratio term becomes 1 because the system is at ambient pressure, and the vaporphase (under the conditions of high temperature and low pressure) was considered ideal $\left(\phi_{\mathrm{i}}=1\right)$, the equilibrium constant can be calculated as the product of the fractions of the components raised to their respective stoichiometric coefficients. The fractions of the components can be expressed as a function of the reaction coordinate $(\varepsilon)$, as shown in Equation 11.

$\mathrm{y}_{\mathrm{i}}=\frac{\mathrm{n}_{\mathrm{i} 0}+v_{\mathrm{i}} \varepsilon}{\mathrm{n}_{0}+\mathrm{v} \varepsilon}$

where $n_{i 0}$ is the initial number of mols of component $i$, and $\mathrm{n}_{0}$ is the total number of initial moles.

From the reactions (1) to (7), the equilibrium constant as a function of temperature was calculated using the Chemical Equilibrium Constant Calculation Program software (SANDLER, 2006) for the NiO/Ni redox system. An analysis of the Gibbs energy variation as a function of temperature was also performed.

\section{RESULTS AND DISCUSSION}

Figure 1 shows the mass variation of the nickelbased OC during the cycles of oxidation and reduction of the $\mathrm{OC}$ obtained in the thermobalance using $\mathrm{H}_{2}$ as fuel. The decrease in mass of the oxygen carrier is the result of the change from the oxidized initial state to a reduced state (reduction cycle) and the increase in mass relative to its complete regeneration (oxidation cycle). During the 4 redox cycles shown in Figure 1, the behavior of OC remains similar, indicating that there was no decrease in its reactivity.

The conversion of solids at $1223 \mathrm{~K}$ is observed in Figure 2, varying the gas atmosphere, where the OC proved to be quite reactive for the $\mathrm{CH}_{4}$ and $\mathrm{H}_{2}$ fuels in $10 \%$ by volume, reaching high conversion in both cases $\left(100 \%\right.$ for $\mathrm{CH}_{4}$ and $90 \%$ for $\left.\mathrm{H}_{2}\right)$ in less

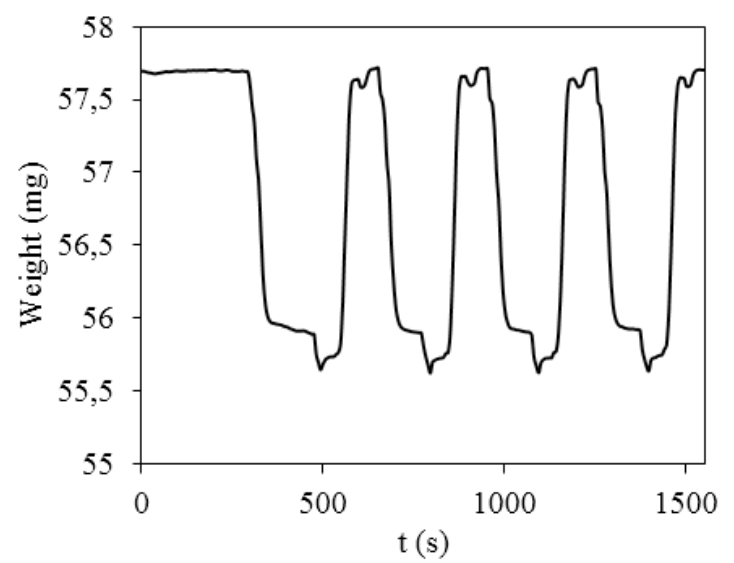

Figure 1. Variation of mass with time during the cycles of reduction and oxidation of the nickel-based OC using $10 \% \mathrm{H}_{2}$ as fuel at $1223 \mathrm{~K}$.

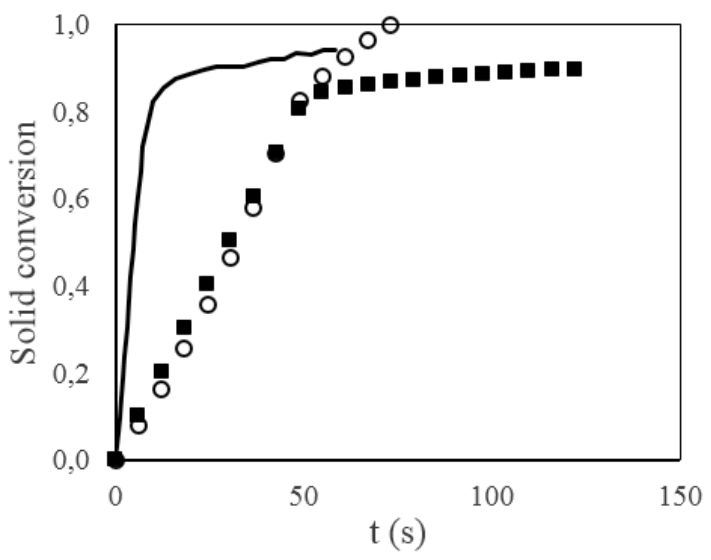

Figure 2. Conversion in the reduction step for the nickel-based $\mathrm{OC}$ using $\mathrm{H}_{2}(\boldsymbol{\bullet})$ and $\mathrm{CH}_{4}(\mathrm{O}) 10 \%$ by volume as fuel (-) (Dueso et al., 2012).

than 2 min. It can also be seen that there is a faster and slower conversion step, which can be attributed to the reductions of the free $\mathrm{NiO}$ in the $\mathrm{OC}$ and the nickel aluminate formed during the calcination step, respectively. Dueso et al. (2012) also observed this event in the reduction of a nickel-based OC at $18 \%$ of mass, using $\mathrm{CH}_{4}\left(15 \%\right.$ vol $+20 \%$ vol $\left.\mathrm{H}_{2} \mathrm{O}\right)$ as a fuel, and a temperature of $1223 \mathrm{~K}$. The maximum solids conversion found by the authors was lower than that observed in this study (96\%); however, this OC presented a higher conversion rate because the temperature was higher.

A higher conversion was found for $\mathrm{CH}_{4}$, probably due to the catalytic effect of metallic nickel on the intermediate reactions during the combustion of $\mathrm{CH}_{4}$, reactions (r3) and (r5), which also give rise to the reaction (r7). Furthermore, there is a higher oxygen stoichiometric ratio $(\mathrm{O} / \mathrm{C})$ when compared to $\mathrm{H}_{2}(\mathrm{O} / \mathrm{H})$ (Abad et al., 2007a; Ortiz et al., 2011). Even though no $\mathrm{H}_{2} \mathrm{O}$ was used in the fuel mixture, probably no coke formation was observed; this event is evidenced by the mass gain of the OC during the reduction cycle. This is because the $\mathrm{O} / \mathrm{C}$ molar ratio used was higher than 1. In addition, the carbon deposited in the $\mathrm{OC}$ can be in the form of $\mathrm{CO}$ and $\mathrm{H}_{2}$ through reaction (6). Ortiz et al. (2011) also reported the absence of coke when working with an $\mathrm{O} / \mathrm{C}$ molar ratio higher than 1 .

In Figure 3, the effect of the fuel gas concentration on the solids conversion of the nickel-based OC is presented. The increase in $\mathrm{H}_{2}$ concentration caused a higher conversion rate, reaching maximum conversion $(93 \%)$ in a shorter time. This implies that the resistances associated with the chemical reaction step are the limiting ones and that, for use in the CLC plant, different times must be used in the reduction reactor for different gas concentrations, in an inverse ratio. Dueso et al. (2012) also found that the increase in gas concentration had a positive effect on solids conversion using a nickel-based OC and carbon monoxide as fuel. 


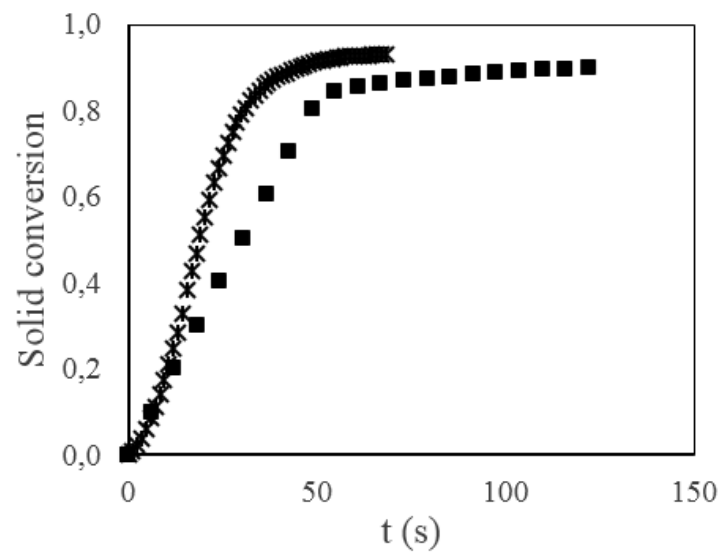

Figure 3. Conversion in the reduction step at $1223 \mathrm{~K}$ for the nickel-based OC using $\mathrm{H}_{2} 10 \%$ ( $)$ and $22 \%$ (*) by volume as fuel.

In order to evaluate the effect of temperature, the nickel-based $\mathrm{OC}$ was reduced at different temperatures using $\mathrm{H}_{2} 10 \%$ by volume as the fuel. Figure 4 shows the reduction profile for each temperature.

The increase in temperature promoted higher solids conversion, indicating that the temperature has a positive effect on solids conversion and conversion rate. From $1173 \mathrm{~K}$ there is not a large variation in the conversion rate, observing only the difference between the maximum conversions. However, at lower temperatures, there is a reduction in both the

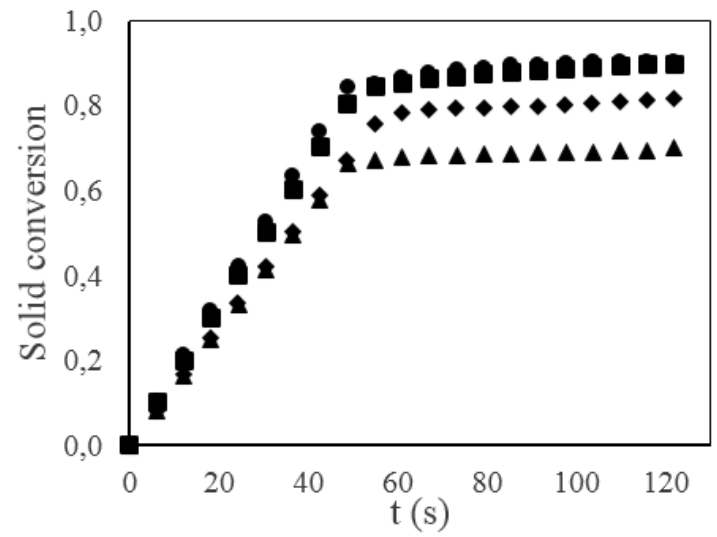

Figure 4. Conversion in the reduction step for the nickel-based $\mathrm{OC}$ using $\mathrm{H}_{2}$ at $10 \%$ by volume fuel at different temperatures: ( $\boldsymbol{\Delta}) 1073 \mathrm{~K},(\diamond) 1123 \mathrm{~K},(\mathbf{\square})$ $1173 \mathrm{~K},(\bullet) 1223 \mathrm{~K}$. conversion rate and the maximum conversion. In this way, it can be stated that heat transfer is also a limitation for the reaction. Gayán et al. (GAYÁN et al., 2012) also observed an increase in the solids conversion rate with the increase in temperature; for achieving maximum conversions, however, the authors used $100 \% \mathrm{H}_{2}$ as fuel.

Table 2 presents the values of $\mathrm{K}$, as well as the correlation coefficient $\left(\mathrm{R}^{2}\right)$ obtained by linearization of the function $\mathrm{g}(\mathrm{x})$ and time for nickel-based $\mathrm{OC}$ using $10 \%$ of $\mathrm{H}_{2}\left(18 \mathrm{Ni}-\mathrm{H}_{2}-1073,18 \mathrm{Ni}-\mathrm{H}_{2}-1123,18 \mathrm{Ni}-\right.$ $\left.\mathrm{H}_{2}-1173,18 \mathrm{Ni}^{-} \mathrm{H}_{2}-1223\right)$ at different temperatures, $22 \%$ of $\mathrm{H}_{2}\left(18 \mathrm{Ni}-22 \mathrm{H}_{2}-1223\right)$ and $10 \%$ of $\mathrm{CH}_{4}(18 \mathrm{Ni}-$ $\left.\mathrm{CH}_{4}-1223\right)$ at $1173 \mathrm{~K}$ (shown in Figure 5). The value of $m$ was extracted from the equation of the line $\ln (-\ln (1$ - $\left.\mathrm{X}_{\mathrm{S}}\right)$ ) versus $\ln (\mathrm{t})$ and represents the possible rate at which the mechanism (nucleus growth or diffusion) occurs.

For the nickel-based OC using $10 \% \mathrm{H}_{2}$ at all temperatures analyzed, the shrinking core model presented the best correlation coefficient, being the most appropriate model to represent the experimental data. However, upon increasing the gas concentration to $22 \%$ by volume $\left(18 \mathrm{Ni}-22 \mathrm{H}_{2}-1223\right)$, the nucleation model better represented the experimental data, presenting a better correlation coefficient. OC $18 \mathrm{Ni}-$ $10 \mathrm{CH}_{4}-1223$ also presented the nucleation model as the best correlation coefficient, being able to describe the experimental data with good precision, as seen in Figure 5. It is also observed that, with the increase in temperature with $10 \%$ of $\mathrm{H}_{2}$, the rate constant increases, which is in accord with Figure 4, where the increase in temperature caused an increase in the conversion rate.

Figure 6 shows the comparison between the models tested with the best $\mathrm{R}^{2}$ and the experimental points for the $\mathrm{OCs}$ at $1223 \mathrm{~K}$.

For the $\mathrm{H}_{2}$ fuel at $10 \%$ volume, it is observed that the shrinking core model does not describe well the data for conversions from the time on average of 60 seconds, where the conversion of solids is between 60 and $80 \%$. This could be linked to the heat transfer associated resistances (as can be seen in Figure 4) and the gas concentration, where the limiting resistances were not sufficient for breaks. Dueso et al. (2012) observed a linear behavior for the reduction of the

Table 2. Kinetic parameters of the reduction reaction of the nickel-based OCs, using $\mathrm{H}_{2}$ and $\mathrm{CH}_{4} 10 \%$ by volume as fuel.

\begin{tabular}{cccccccc}
\hline \multirow{2}{*}{$\mathbf{O C}$} & \multirow{2}{*}{$\mathbf{M}$} & \multicolumn{2}{c}{ Nucleation } & \multicolumn{2}{c}{ Shrinking-core } & \multicolumn{2}{c}{ Diffusion } \\
\cline { 3 - 7 } & & $\mathbf{K}$ & $\mathbf{R}^{\mathbf{2}}$ & $\mathbf{K}$ & $\mathbf{R}^{\mathbf{2}}$ & $\mathbf{k}$ & $\mathbf{R}^{\mathbf{2}}$ \\
\hline $18 \mathrm{Ni}-10 \mathrm{H}_{2}-1073$ & 0.879 & 0.019 & 0.933 & 0.008 & 0.9910 & 0.021 & 0.946 \\
$18 \mathrm{Ni}-10 \mathrm{H}_{2}-1123$ & 1.034 & 0.022 & 0.952 & 0.009 & 0.9860 & 0.019 & 0.955 \\
$18 \mathrm{Ni}-10 \mathrm{H}_{2}-1173$ & 1.072 & 0.028 & 0.945 & 0.011 & 0.9820 & 0.022 & 0.953 \\
$18 \mathrm{Ni}-10 \mathrm{H}_{2}-1223$ & 1.064 & 0.030 & 0.928 & 0.011 & 0.9774 & 0.023 & 0.943 \\
$18 \mathrm{Ni}-22 \mathrm{H}_{2}-1223$ & 1.477 & 0.043 & 0.990 & 0.017 & 0.9710 & 0.030 & 0.980 \\
$18 \mathrm{Ni}-10 \mathrm{CH}_{4}-1223$ & 1.679 & 0.026 & 0.995 & 0.009 & 0.9820 & 0.017 & 0.868 \\
\hline
\end{tabular}




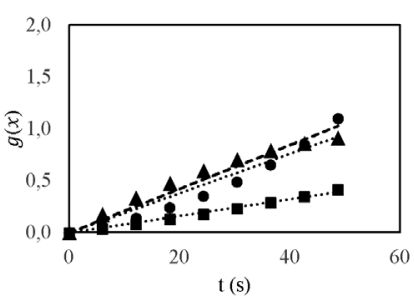

(a)

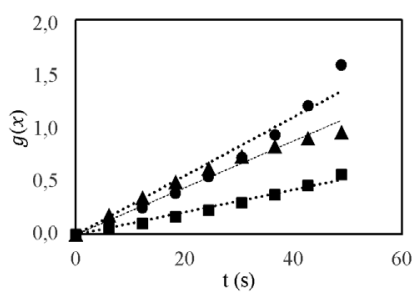

(c)

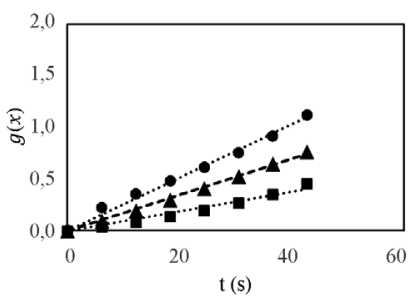

(e)

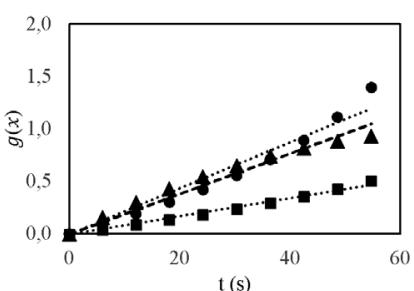

(b)

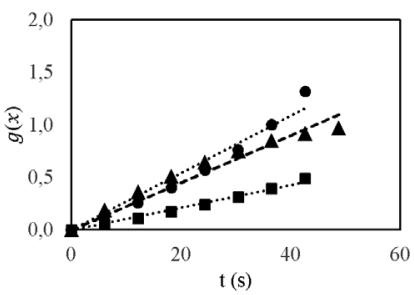

(d)

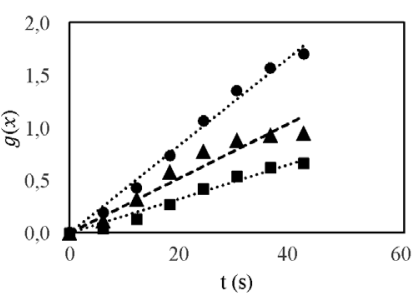

(f)

Figure 5. Linear fits for models, $\mathrm{g}(\mathrm{x})$ as a function of time. (a) $10 \%$ of $\mathrm{H}_{2}$ at $1073 \mathrm{~K}$, (b) $10 \%$ of $\mathrm{H}_{2}$ at 1123 $\mathrm{K}$, (c) $10 \%$ of $\mathrm{H}_{2}$ at $1173 \mathrm{~K}$, (d) $10 \%$ of $\mathrm{H}_{2}$ at $1223 \mathrm{~K}$, (e) $22 \%$ of $\mathrm{H}_{2}$ at $1223 \mathrm{~K}$, (f) $10 \%$ of $\mathrm{CH}_{4}^{2}$ at $1223 \mathrm{~K}$. Shrinking core model $(\boldsymbol{\bullet})$, nucleation model $(\bullet)$ and diffusion model $(\boldsymbol{\Delta})$.

nickel-based $\mathrm{OC}$ for the $\mathrm{H}_{2}$ fuel, which is also observed in this study up to $80 \%$ conversion. Considering that the authors used higher temperatures $(>1243 \mathrm{~K})$ it is possible that limiting resistances are associated with a drop in the conversion rate. The shrinking core model has been used to describe the reactivity of nickel-based OC in the literature (Hancock and Sharp, 1972; Abad et al., 2007b) and can be applied to kinetic calculations and represent what occurs during the reaction.

The nucleation model can describe the conversion rate of the $\mathrm{CH}_{4}$ combustion reaction with better efficiency. This model has been applied to describe the reaction rate of the reduction reaction of nickel-based OC. Sedor et al. (2008) using a $20 \%$ mass of nickel oxide, observed that, for the $\mathrm{CH}_{4}$ combustion reaction, the nucleation model described better the experimental data of reaction rate when compared to the shrinking core model.

The methodology used to determine the kinetic parameters was also tested with the experimental data found by Dueso et al. (2012) quoted in Figure 2. A rate constant of $0.16 \mathrm{~s}^{-1}$ was obtained, similar to that found by the authors $\left(0.15 \mathrm{~mol}^{1-\mathrm{n}} \mathrm{m}^{2-3 \mathrm{n}} \mathrm{s}^{-1}\right)$ for the reduction of $\mathrm{NiO}$. The nucleation model also correlated satisfactorily the experimental data found
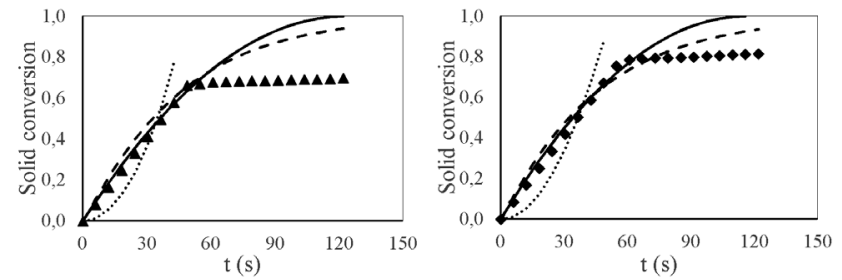

(a)

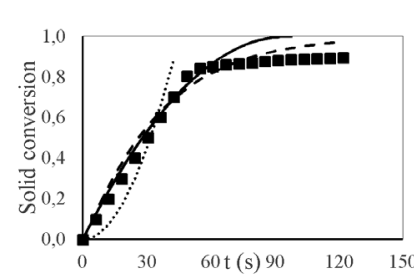

(c)

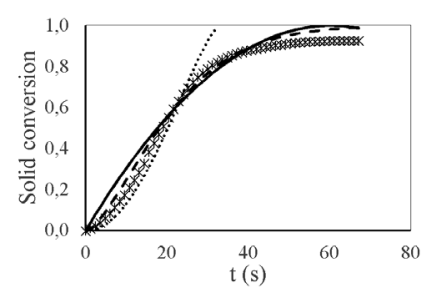

(e)

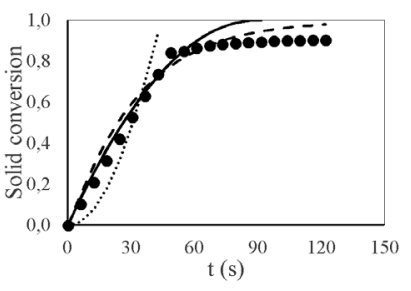

(d)

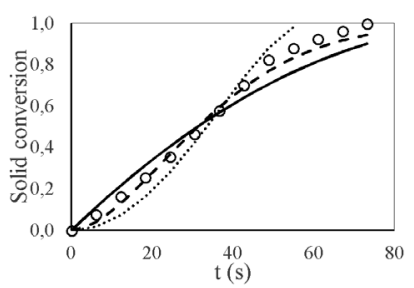

(f)

Figure 6. Conversion of solids in the reduction step of nickel-based OCs for different fuels and temperatures: (a) $10 \%$ of $\mathrm{H}_{2}$ at $1073 \mathrm{~K}$, (b) $10 \%$ of $\mathrm{H}_{2}$ at $1123 \mathrm{~K}$, (c) $10 \%$ of $\mathrm{H}_{2}$ at $1173 \mathrm{~K}$, (d) $10 \%$ of $\mathrm{H}_{2}$ at $1223 \mathrm{~K}$, (e) $22 \%$ of $\mathrm{H}_{2}$ at $1223 \mathrm{~K}$, (f) $10 \%$ of $\mathrm{CH}_{4}$ at $1223 \mathrm{~K}$. Shrinking core model (-), nucleation model (---) and diffusion model $(\cdots)$. Symbols $(\boldsymbol{\Lambda}, \bullet, \boldsymbol{\bullet}, \bullet, \times$,$) are experimental$ data.

by the authors, presenting a correlation coefficient of 0.9937.

From the kinetic constants obtained for each temperature in the reduction reaction of the nickelbased OC with $10 \% \mathrm{H}_{2}$, it was possible to calculate the activation energy $\left(\mathrm{E}_{\mathrm{a}}\right)$ and the pre-exponential factor $\left(\mathrm{A}_{0}\right)$. Figure 7 shows the straight line obtained by the linearization of Equation 5.

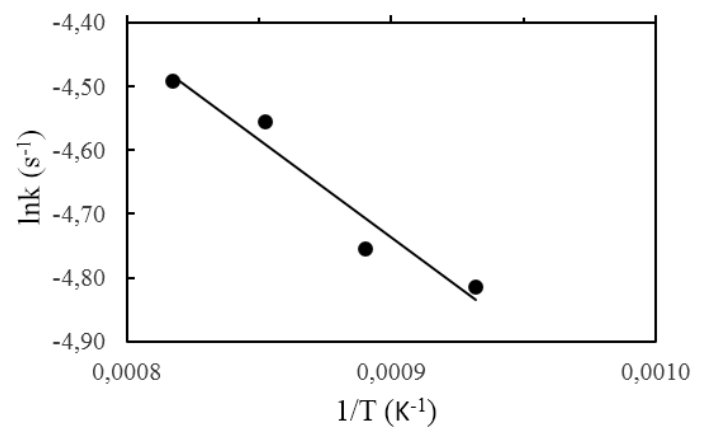

Figure 7. Linearization of the Arrhenius equation for the reduction reaction of nickel-based OCs at different temperatures with $\mathrm{H}_{2}$ at $10 \%$. 
The values obtained from the equation of the straight line for the activation energy and the exponential factor were $25.53 \mathrm{~kJ} / \mathrm{mol}$ and $1.39 \times 10^{-1} \mathrm{~s}^{-1}$, respectively. The coefficient of correlation of the obtained straight line was 0.945 , which is satisfactory, being possible to use the data of $\mathrm{E}_{\mathrm{a}}$ and $\mathrm{A}_{0}$ to determine the value of the kinetic constant at different temperatures, allowing the simulation of the conversion rate. The low activation energy shows that the reaction rate does not show strong dependence on temperature. This is also evident when observing Figure 4, where, with the variation of temperature, the greater effect is identified in the conversion of solids.

Abad et al. (2007b), using the shrinking core model, which best correlated the experimental data, obtained values of the activation energy and preexponential factor of $26 \mathrm{~kJ} / \mathrm{mol}$ e $9.3 \times 10^{-3} \mathrm{~mol}^{1-}$ ${ }^{n} \mathrm{~m}^{3 \mathrm{n}-2} \mathrm{~s}^{-1}$, respectively, for a Nickel-based OC at $40 \%$ by mass using $20 \%$ by volume of $\mathrm{H}_{2}$ as the fuel. The results do not differ much from those found in this study, considering that a higher concentration of nickel in the $\gamma$-alumina support was used $(40 \%$ and $18 \%$ in this study) and a higher gas concentration (20\% in the study of Abad et al (2007b) and $10 \%$ in this study). Dueso et al. (2012) used a nickel-based OC at $18 \%$ by mass and studied its reduction reaction rate for $\mathrm{H}_{2}$ fuel at $5 \%$ volume, obtaining results for activation energy of $5 \mathrm{~kJ} / \mathrm{mol}$ and pre-exponential factor of $1.5 \times 10^{-1}$ $\mathrm{mol}^{1-\mathrm{n}} \mathrm{m}^{3 \mathrm{n}-2} \mathrm{~s}^{-1}$, using a combined model.

In addition to the reactivity analyses of OCs, it is important to note that a thermodynamic study was conducted to see if the $\mathrm{OC}$ is stable and capable of converting all the reagent into product. A Figure 8 shows the thermodynamic analysis through the equilibrium constant $\left(\mathrm{K}_{e q}\right)$ as a function of temperature and the Gibbs free energy variation for the combustion reaction of $\mathrm{H}_{2}$ and $\mathrm{CH}_{4}$, for the set of reactions (1) to (7). In Table 3 , the $\mathrm{K}_{\mathrm{eq}}$ and the Gibbs energy variation can be observed for the possible reactions that occur in the reduction reactor, at $1223 \mathrm{~K}$.

The values found for the equilibrium constants for all reactions $\left(\ln \mathrm{K}_{\mathrm{eq}}>3\right)$ at the investigated temperatures ( 273 to $1273 \mathrm{~K}$ ) were quite high only at temperatures higher than $973 \mathrm{~K}$, showing that the complete conversion of the fuels was obtained. Similar results were reported by Adenez et al. (2012) and Jerndal et al. (2006). The increase in temperature causes a increase in the equilibrium constant, although high temperatures are required for the complete reduction of $\mathrm{OC}$, as seen in Figure 4. Still in Figure 8, the higher $\mathrm{K}_{\mathrm{eq}}$ values for the reactions ( $\mathrm{r} 1)$ or ( 2 2), using $\mathrm{CH}_{4}$ as fuel, show that $\mathrm{NiO}$ is more favorable for this fuel, as seen in the reactivity data (Figure 2). Among the combustion and reforming reactions of $\mathrm{CH} 4,(1)$ and (2) respectively, $\mathrm{K}_{\mathrm{eq}}$ is higher for reaction ( $\mathrm{r} 1$ ), showing that it is the most thermodynamically favorable. The Gibbs energy variation is minimal at temperatures above $973 \mathrm{~K}$ for

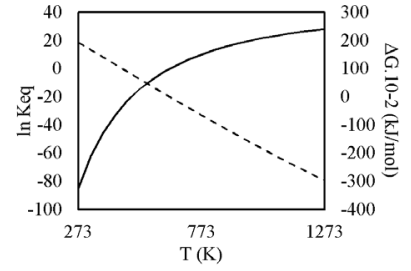

(1)

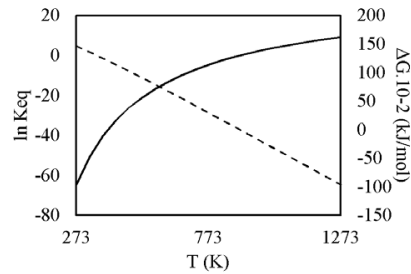

(3)

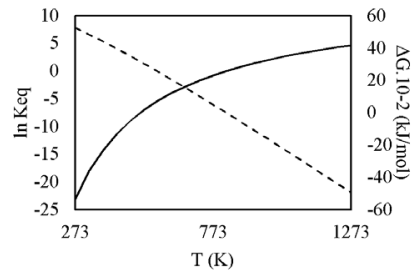

(5)

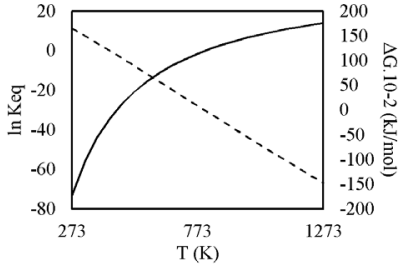

(2)

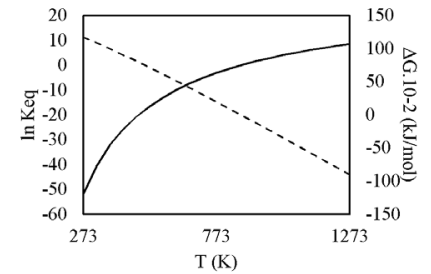

(4)

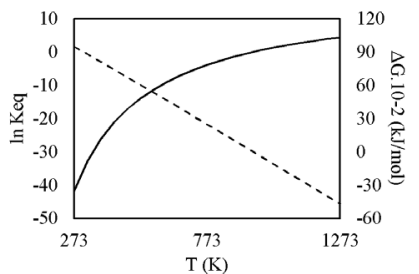

(6)

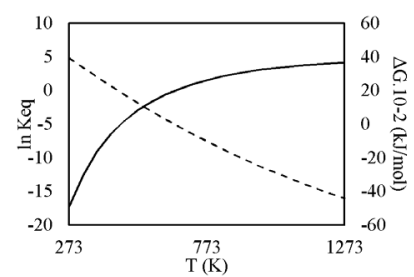

(7)

Figure 8. Equilibrium constant (-) and Gibbs free energy variation (---) as a function of temperature for the reactions occurring in the reduction reactor (described in Table 3) using different fuels.

chemical recirculation for combustion, indicating that the combustion reaction occurs spontaneously.

The reaction coordinate, calculated by Equations 10 and 11 , for the temperature of $1223 \mathrm{~K}$, was 0.999 and 0.853 mols for the $\mathrm{CH}_{4}$ and $\mathrm{H}_{2}$ fuel (reaction 1 and 7), respectively, indicating the degree of progress of the reaction, that is, how much the reaction progressed in equilibrium. For the calculation of the reaction coordinate, only the species in the vapor phase were considered and the substances in the solid phase were pure and did not mix. Comparing the reaction coordinates for the two reactions, the combustion reaction of $\mathrm{CH}_{4}$ from the reduction of $\mathrm{NiO}$ is more favorable thermodynamically than for $\mathrm{H}_{2}$, as was also seen in Figure 2. For the other reactions with $\mathrm{CH}_{4}$, the reaction coordinate is near to 1 , which indicates that the conversion is high. De Diego et al. (2009) reported that, due to thermodynamic constraints or temperature not sufficiently high, $\mathrm{CH}_{4}$ combustion was not complete. 
Table 3. Equilibrium constant and Gibbs energy for different reactions at $1223 \mathrm{~K}$.

\begin{tabular}{lccc}
\hline \multicolumn{1}{c}{ Reaction } & $\ln \mathbf{K}_{\mathrm{eq}}$ & $\boldsymbol{\Delta G}(\mathbf{k J} / \mathbf{m o l})$ & Reaction coordinate \\
\hline$(\mathrm{r} 1) \mathrm{CH}_{4}+4 \mathrm{NiO} \leftarrow \rightarrow \mathrm{CO}_{2}+2 \mathrm{H}_{2} \mathrm{O}+4 \mathrm{Ni}$ & 27.1 & -275.36 & 0.999 \\
$(\mathrm{r} 2) \mathrm{CH}_{4}+\mathrm{NiO} \leftarrow \rightarrow \mathrm{CO}+\mathrm{Ni}+2 \mathrm{H}_{2}$ & 13.0 & -132.35 & 0.999 \\
$(\mathrm{r} 3) \mathrm{CH}_{4}+\mathrm{H}_{2} \mathrm{O} \leftarrow \rightarrow \mathrm{CO}+3 \mathrm{H}_{2}$ & 8.2 & -83.24 & 0.979 \\
$(\mathrm{r} 4) \mathrm{CH}_{4}+2 \mathrm{H}_{2} \mathrm{O} \leftarrow \rightarrow \mathrm{CO}_{2}+4 \mathrm{H}_{2}$ & 7.8 & -78.76 & 0.91 \\
$(\mathrm{r} 5) \mathrm{CH}_{4} \leftarrow \rightarrow \mathrm{C}+2 \mathrm{H}_{2}$ & 4.3 & -43.69 & 0.994 \\
$(\mathrm{r} 6) \mathrm{C}+\mathrm{H}_{2} \mathrm{O} \leftarrow \rightarrow \mathrm{CO}+\mathrm{H}_{2}$ & 3.9 & -39.55 & 0.997 \\
$(\mathrm{r} 7) \mathrm{H}_{2}+\mathrm{NiO} \leftarrow \rightarrow \mathrm{H}_{2} \mathrm{O}+\mathrm{Ni}$ & 4.06 & -41.25 & 0.853 \\
\hline
\end{tabular}

\section{CONCLUSIONS}

In this study it was possible to verify that the nickelbased OC is quite reactive, being suitable for use in chemical looping combustion, showed high reactivity for $\mathrm{H}_{2}$ and $\mathrm{CH}_{4}$ fuel, achieving a conversion of over $90 \%$ for temperatures of $1223 \mathrm{~K}$. There was a positive effect of the temperature, increasing the reactivity of the $\mathrm{OC}$ and improving its performance in terms of the conversion rate, where a faster final conversion was observed. The same effect was noted with the increase of gas concentration. The kinetic study performed with the main resistances associated with gas-solid processes satisfactorily described the reaction kinetics of $\mathrm{H}_{2}$ and $\mathrm{CH}_{4}$ for nickel-based OCs, using the shrinking core model for the $10 \% \mathrm{H}_{2}$ and the nucleation model for $\mathrm{CH}_{4}$ and $22 \%$ of $\mathrm{H}_{2}$ as fuel. The equilibrium constants obtained for the temperature range used in a CLC plant $(1073$ to $1223 \mathrm{~K})$ for the reaction indicate that nickel oxide was thermodynamically favorable for both fuels $\left(\mathrm{H}_{2}\right.$ and $\left.\mathrm{CH}_{4}\right)$, converting practically all of the fuel into products.

\section{ACKNOWLEDGMENT}

The authors are grateful to the $14^{\circ}$ Human Resources Program of the National Oil Agency for financial support.

\section{REFERENCES}

Abad, A., Adánez, J., García-Labiano, F., De Diego, L.F., Gayán, P., Celaya, J. Mapping of the range of operational conditions for $\mathrm{Cu}-, \mathrm{Fe}-$, and Ni-based oxygen carriers in chemical-looping combustion. Chemical Engineering Science, 62, 533-549 (2007a). https://doi.org/10.1016/j.ces.2006.09.019

Abad, A., García-Labiano, F., De Diego, L.F., Gayán, P., Adánez, J. Reduction kinetics of $\mathrm{Cu}-$, Ni-, and Fe-based oxygen carriers using syngas $(\mathrm{CO}$ $+\mathrm{H}_{2}$ ) for chemical-looping combustion. Energy and Fuels, 21, 1843-1853 (2007b). https://doi. org/10.1021/ef070025k

Adanez, J., Abad, A., Garcia-Labiano, F., Gayan, P., De Diego, L.F. Progress in Chemical-Looping Combustion and Reforming technologies, Progress in Energy and Combustion Science, 38, 215-282 (2012). https://doi.org/10.1016/j.pecs.2011.09.001
Adánez, J., De Diego, L.F., García-Labiano, F., Gayán, P., Abad, A., Palacios, J.M. Selection of oxygen carriers for chemical-looping combustion. Energy and Fuels, 18, 371-377 (2004). https://doi. org/10.1021/ef0301452

De Diego, L.F., Ortiz, M., García-Labiano, F., Adánez, J., Abad, A., Gayán, P. Hydrogen production by chemical-looping reforming in a circulating fluidized bed reactor using $\mathrm{Ni}$-based oxygen carriers. Journal of Power Sources, 192, 27-34 (2009). https://doi.org/10.1016/j.jpowsour.2008.11.038

Dueso, C., Ortiz, M., Abad, A., García-Labiano, F., De Diego, L.F., Gayán, P., Adánez, J. Reduction and oxidation kinetics of nickel-based oxygen-carriers for chemical-looping combustion and chemicallooping reforming. Chemical Engineering Journal, 188, 142-154 (2012). https://doi.org/10.1016/j. cej.2012.01.124

Forutan, H.R., Karimi, E., Hafizi, A., Rahimpour, M.R., Keshavarz, P. Expert representation chemical looping reforming: A comparative study of $\mathrm{Fe}, \mathrm{Mn}$, $\mathrm{Co}$ and $\mathrm{Cu}$ as oxygen carriers supported on $\mathrm{Al}_{2} \mathrm{O}_{3}$. Journal of Industrial and Engineering Chemistry, 21, 900-911 (2015). https://doi.org/10.1016/j. jiec.2014.04.031

Gayán, P., Adánez-Rubio, I., Abad, A., De Diego, L.F., García-Labiano, F., Adánez, J. Development of $\mathrm{Cu}$-based oxygen carriers for Chemical-Looping with Oxygen Uncoupling (CLOU) process. Fuel, 96, 226-238 (2012). https://doi.org/10.1016/j. fuel.2012.01.021

Han, L., Zhou, Z., Bollas, G.M. Heterogeneous modeling of chemical-looping combustion. Part 2: Particle model. Chemical Engineering Science, 113, 116-128 (2014). https://doi.org/10.1016/j. ces.2014.03.030

Han, L., Zhou, Z., Bollas, G.M. Model-Based Analysis of Chemical-Looping Combustion Experiments . Part I : Structural Identifiability of Kinetic Models for NiO Reduction. AIChE Journal, 62, 2419-2431 (2016a). https://doi.org/10.1002/aic.15225

Han, L., Zhou, Z., Bollas, G.M. Model-Based Analysis of Chemical-Looping Combustion Experiments . Part II : Optimal Design of $\mathrm{CH}_{4}-\mathrm{NiO}$ Reduction Experiments. AIChE Journal, 62, 2432-2446 (2016b). https://doi.org/10.1002/aic.15242 
Hancock, J.D., Sharp, J.H. Method of Comparing Solid-State Kinetic Data and Its Application to the Decomposition of Kaolinite, Brucite, and $\mathrm{BaCO}_{3}$. Journal of the American Ceramic Society, 55, $74-77$ (1972). https:// doi.org/10.1111/j.1151-2916.1972.tb11213.x

Jerndal, E., Mattisson, T., Lyngfelt, A. Thermal analysis of chemical-looping combustion. Chemical Engineering Research and Design, 84, 795-806 (2006). https://doi.org/10.1205/cherd05020

Luo, M., Wang, S., Wang, L., Lv, M. Reduction kinetics of iron-based oxygen carriers using methane for chemical-looping combustion. Journal of Power Sources, 270, 434-440 (2014). https://doi. org/10.1016/j.jpowsour.2014.07.100

Nordness, O., Han, L., Zhou, Z., Bollas, G.M. HighPressure Chemical-Looping of Methane and Synthesis Gas with $\mathrm{Ni}$ and $\mathrm{Cu}$ Oxygen Carriers. Energy Fuels, 30, 504-514 (2016). https://doi. org/10.1021/acs.energyfuels.5b01986

Ortiz, M., Abad, A., De Diego, L.F., García-Labiano, F., Gayán, P., Adánez, J. Optimization of hydrogen production by Chemical-Looping auto-thermal
Reforming working with Ni-based oxygencarriers. International Journal of Hydrogen Energy, 36, 9663-9672 (2011). https://doi.org/10.1016/j. ijhydene.2011.05.025

Pröll, T., Bolhàr-Nordenkampf, J., Kolbitsch, P., Hofbauer, H. Syngas and a separate nitrogen/argon stream via chemical looping reforming - A 140 kW pilot plant study. Fuel, 89, 1249-1256 (2010). https://doi.org/10.1016/j.fuel.2009.09.033

Sandler, S. I. Chemical Equilibrium Constant Program, J. Wiley and Sons, Inc., 2006.

Sedor, K.E., Hossain, M.M., De Lasa, H.I. Reduction kinetics of a fluidizable nickel-alumina oxygen carrier for chemical-looping combustion. Canadian Journal of Chemical Engineering, 86, 323-334 (2008). https://doi.org/10.1002/cjce. 20072

Zhou, Z., Han, L., Bollas, G.M. ScienceDirect Kinetics of $\mathrm{NiO}$ reduction by $\mathrm{H}_{2}$ and $\mathrm{Ni}$ oxidation at conditions relevant to chemical-looping combustion and reforming. International Journal of Hydrogen Energy, 39, 8535-8556 (2014). https:// doi.org/10.1016/j.ijhydene.2014.03.161 